Lepr Rev (1999) 70, 21-27

\title{
Childhood leprosy in an endemic area
}

\author{
ABRAHAM SELVASEKAR * JOSEPH GEETHA*, \\ KURIAN NISHA ${ }^{* *}$, N. MANIMOZHI ${ }^{*}$, K. JESUDASAN ${ }^{*}$ \\ \& P. S. S. RAO* \\ *Branch of Epidemiology and Leprosy Control, ${ }^{* *}$ Branch of Biostatistics, \\ Schieffelin Leprosy Research and Training Centre, Karigiri, \\ Tamil Nadu 632 106, India
}

Accepted for publication 10 December 1998

\begin{abstract}
Summary A study was done on 794 new cases of leprosy among children (aged 0-14 years) detected and treated with MDT during 1990-1995 in Gudiyatham Taluk, South India. Incidence rates of leprosy and proportion of multibacillary cases increased with age, while bacillary + tuberculoid was most common. Over $80 \%$ had a single patch and most children were detected through surveys. Nearly $30 \%$ had history of household contacts with leprosy, mostly parents or grandparents. Reactions and relapses were not uncommon. The findings emphasize the need for more careful surveys for case detection and better follow-up in case management.
\end{abstract}

\section{Introduction}

Several aspects of transmission and epidemiology of leprosy are still unclear or remain controversial. ${ }^{1-6}$ Studies on leprosy among children could unravel some of these questions, especially if the manifestations and process of discovery are carefully observed. Reports on childhood leprosy are based on cross-sectional prevalence surveys of institutionalized or general populations. ${ }^{7-9}$ Transmission within households based on contact surveys has also been reported. ${ }^{1-9}$ The advent of multidrug therapy (MDT) gave hope of a rapid decline in leprosy, especially among children. The fact that such hopes were not realized even after 15 years, especially in areas of good coverage and monitoring of the control programme, has raised concern and the need for more intensive studies.

A study on childhood leprosy was undertaken to record changes in the presentation of the disease 10 years after the introduction of MDT in Gudiyatham Taluk. The profile of these children at detection and their follow-up in terms of relapses and complications are presented and discussed in this paper.

Correspondence to: Dr P. S. S. Rao, Director, S. L. R. \& T. C., Karigiri, Vellore Dt. 632 106, Tamil Nadu, India $\mathrm{K}$. Jesudasan is deceased 


\section{Materials and methods}

The study was done in Gudiyatham Taluk on an area highly endemic for leprosy, situated in North Arcot Ambedkar District of Tamil Nadu, India. It had a population of 385,228 in 1961, swelling to about 576,146 in 1991. A leprosy control unit of the Schieffelin Leprosy Research and Training Centre (SLR \& TC) was established in 1962. A population survey of the area carried out in 1966 showed an overall prevalence rate of 29/1000; the lepromatous index for children below 14 years in the 1966 survey was 3.7. ${ }^{10}$ Periodically, this population was screened for new cases through general surveys, contact surveys and school surveys. Voluntary reporting was encouraged through health education of the community. Cases detected by paramedical workers or non-medical supervisors were confirmed by medical officers. Smears were taken from four different sites: right ear, left forehead, right chin and left buttock or thigh. Suspect patients who did not have the cardinal signs of leprosy were kept under observation for a period of 3 months and reviewed, and/or a skin biopsy taken.

Patients were classified according to the criteria of Ridley and Jopline, ${ }^{11}$ and were reclassified into paucibacillary $(\mathrm{PB})$ multibacillary $(\mathrm{MB})$ as suggested by the World Health Organisation. ${ }^{12}$ When the aggregate of skin and truncal nerve lesions reached 10 in a patient, the MBR-MDT (multibacillary regimen) was prescribed. Anyone showing a positive skin smear irrespective of the clinical classification was treated in the same way. Detailed case records were kept and stored in a computer data bank.

All children who were less than 15 years of age at their last birthday when registered during 1990-95 were included. They were divided into three age groups: group 1, children below 5 years of age; group 2, children between 5 and 9 years of age and group 3, those between 10 and 14 years of age.

\section{Results}

A total of 2540 leprosy patients were registered during 1990-95. Of these, 794 (31.3\%) were children, whose ages and sex are shown in Table 1.

There were 36 children in group 1, 290 in group 2 and 468 in group 3. Except among the under-fives, there was a slight preponderance of males within $\mathrm{M}: \mathrm{F}$ ratio being $1 \cdot 25: 1$.

\section{INCIDENCE}

Age-sex specific incidence rates of leprosy were computed using the estimated population in

Table 1. Childhood leprosy cases detected during $1990-95$ by age and sex

\begin{tabular}{lcccccr}
\hline \multicolumn{7}{c}{ Age (years) } \\
\cline { 2 - 7 } Sex & (Gr. 1) & (Gr. 2) & $\begin{array}{c}\text { (Gr. 3) } \\
10-14\end{array}$ & $\begin{array}{c}\text { All children } \\
0-14\end{array}$ & $\begin{array}{c}\text { Adults } \\
15 \text { and over }\end{array}$ & Total \\
\hline Male & $0-4$ & $5-9$ & 248 & 425 & 885 & 1310 \\
Female & 16 & 61 & 220 & 369 & 861 & 1230 \\
Total & 20 & 129 & 468 & 794 & 1746 & 2540 \\
\hline
\end{tabular}


Table 2. Estimated annual incidence rates (per 10,000)* among children by age and sex

\begin{tabular}{lcccccc}
\hline & \multicolumn{7}{c}{ Age (years) } \\
\cline { 2 - 7 } & Sex & (Gr. 1) & (Gr. 2) & (Gr. 3) & All children & Adults \\
& $0-4$ & $5-9$ & $10-14$ & $0-14$ & 15 and over & Total \\
\hline Male & 0.75 & 8.17 & 11.90 & 6.86 & 7.13 & 7.04 \\
Female & 0.99 & 6.94 & 11.10 & 6.31 & 7.46 & 7.07 \\
Total & 0.87 & 7.57 & 11.51 & 6.59 & 7.29 & 7.06 \\
& & & & & & \\
\hline
\end{tabular}

*Based on age-sex distribution of estimated population in Gudiyatham Taluk, 1993.

the various age groups based on the National Census of Gudiyatham Taluk. The findings are given in Table 2 .

The incidence rates (per 10,000) increased steadily from 0.87 in group 1 to 7.57 in group 2 and 11.51 in group 3.

TYPE OF LEPROSY

The different types of leprosy affecting the children are presented in Table 3.

Only $16(2 \%)$ were classified as MB, of which only one was a pure lepromatous leprosy (LL) $(0 \cdot 1 \%)$. None in group 1, $4(1.4 \%)$ in group 2 and $12(2.5 \%)$ in group 3 had MB leprosy. Sixteen children had positive skin smears taken from routine or selective sites. Borderline tuberculoid (BT) was the commonest type encountered in the children in all three groups.

\section{MODE OF DETECTION}

Surveys remained the main mode of detection of leprosy in children. School surveys resulted in $328(41.3 \%)$ patients, general survey in $212(26.7 \%)$ and survey of contacts in $73(9.2 \%)$.

Table 3. Childhood leprosy by age and classification

\begin{tabular}{|c|c|c|c|c|c|c|}
\hline \multirow[b]{3}{*}{ Classification } & \multicolumn{6}{|c|}{ Age (years) } \\
\hline & $\begin{array}{c}\text { (Gr. 1) } \\
0-4\end{array}$ & $\begin{array}{c}\text { (Gr. 2) } \\
5-9\end{array}$ & \multicolumn{2}{|c|}{$\begin{array}{c}\text { (Gr. 3) } \\
10-14\end{array}$} & \multicolumn{2}{|c|}{$\begin{array}{l}\text { (All) } \\
0-14\end{array}$} \\
\hline & No. $\%$ & No. $\%$ & No. & $\%$ & No. & $\%$ \\
\hline PN & $-\quad-$ & $-\quad-$ & 2 & 0.4 & 2 & 0.3 \\
\hline IND & 25.5 & $31 \quad 10.6$ & 47 & 10.0 & 80 & 10.1 \\
\hline TT & $13 \quad 36.1$ & $84 \quad 29.0$ & 118 & 25.2 & 215 & 27.1 \\
\hline $\mathrm{BT}$ & $21 \quad 58.3$ & $171 \quad 59.0$ & 289 & 61.8 & 481 & 60.5 \\
\hline BL & $-\quad-$ & $\begin{array}{ll}4 & 1.4\end{array}$ & 11 & 2.3 & 15 & 1.9 \\
\hline LL & -- & -- & 1 & 0.2 & 1 & 0.1 \\
\hline Total & 36100.0 & 290100.0 & 468 & 100.0 & 794 & 100.0 \\
\hline
\end{tabular}

$\mathrm{PN}=$ pure neutral, $\mathrm{IND}=$ indeterminate, $\mathrm{TT}=$ tuberculoid, $\mathrm{BT}=$ borderline tuberculoid, $\mathrm{BL}=$ borderline lepromatous, $\mathrm{LL}=$ lepromatous leprosy. 
Table 4. Age and duration of the disease (in years)

\begin{tabular}{lccrrr}
\hline & \multicolumn{4}{c}{ Age (years) } \\
\cline { 2 - 6 } & & & & \\
Duration of & (Gr. 1) & $($ Gr. 2$)$ & (Gr. 3) & $0-14$ \\
leprosy (years) & $0-4$ & $5-9$ & $10-14$ & No. & $\%$ \\
\hline$\leq 1$ & 35 & 268 & 400 & 703 & $88 \cdot 5$ \\
$2-3$ & 1 & 16 & 46 & 63 & $8 \cdot 0$ \\
$4-5$ & - & 4 & 14 & 18 & $2 \cdot 3$ \\
$>5$ & - & 2 & 8 & 10 & $1 \cdot 3$ \\
Total & 36 & 290 & 468 & 794 & $100 \cdot 0$ \\
& & & & & \\
\hline
\end{tabular}

Only $181(22.8 \%)$ children were voluntarily brought forward. The classification of leprosy and site of lesion did not vary significantly according to mode of detection.

\section{HOUSEHOLD CONTACT}

Family members of a leprosy patient living together under the same roof and partaking of meals from a common kitchen were called household contacts. Overall, 237 (29.8\%) gave a history of contact within the household. Forty-four percent of the children in group 1 had a member of the family with leprosy. In groups 2 and 3, the positive history of contact was elicited in a smaller proportion of children-just $29.5 \%$. The index case was a parent in $40 \%$ of those giving a history of household contact, a grandparent in $14 \%$, a sibling in $18 \%$ and a distant relative for others. Fifteen children were exposed to multiple cases in the household. The ratio of MB/PB among household contacts developing leprosy was not different from that of others; six of $16 \mathrm{MB}$ were from household contacts, two from multiple case families.

\section{DURATION OF DISEASE}

The duration of disease as stated by the parents is presented in Table 4 .

The duration of disease was mostly under a year, except in the older age groups. It is surprising that there are missed cases with duration more than 3 years.

\section{NUMBER OF PATCHES}

Nearly $83 \%$ of the children had a single patch, as displayed in Table 5 .

Two, three and four to five patches occurred in 8,2 and $2 \%$ of the children, respectively. Multiple patches occurred in 5\%.

\section{DISTRIBUTION OF PATCHES}

The distribution of the patches was on the exposed parts of the body, in order of magnitude, hand, face, leg and knee, in $546(68.7 \%)$ children, while $242(30.5 \%)$ children had patches on the covered parts of the body, thigh, trunk and buttock. 
Table 5. Age and patches

\begin{tabular}{|c|c|c|c|c|c|}
\hline \multirow[b]{3}{*}{ Patches } & \multicolumn{5}{|c|}{ Age (years) } \\
\hline & \multirow{2}{*}{$\begin{array}{c}\text { (Gr. 1) } \\
0-4\end{array}$} & \multirow{2}{*}{$\begin{array}{c}\text { (Gr. 2) } \\
5-9\end{array}$} & \multirow{2}{*}{$\begin{array}{c}\text { (Gr. 3) } \\
10-14\end{array}$} & \multicolumn{2}{|c|}{$\begin{array}{l}\text { (All) } \\
0-14\end{array}$} \\
\hline & & & & No. & $\%$ \\
\hline 0 & - & - & 5 & 5 & $0 \cdot 6$ \\
\hline 1 & 28 & 240 & 392 & 660 & $83 \cdot 1$ \\
\hline 2 & 3 & 23 & 34 & 60 & $7 \cdot 6$ \\
\hline 3 & 1 & 9 & 7 & 17 & $2 \cdot 1$ \\
\hline $4-5$ & 2 & 7 & 5 & 14 & 1.8 \\
\hline$>5$ & 2 & 11 & 25 & 38 & $4 \cdot 8$ \\
\hline Total & 36 & 290 & 486 & 794 & $100 \cdot 0$ \\
\hline
\end{tabular}

FOLLOW-UP

Based on records, data on follow-up were studied up to the end of 1996. Seventeen children left the study area, 11 after released from treatment (RFT) after paucibacillary regimen (PBR) and four during (PBR) treatment. Two smear positive cases also left during the course of treatment.

RELAPSES

Despite their completing 6 months of PBR prescribed according to body weight, relapses occurred in 13 children with PB leprosy. Three occurred during the 2-year surveillance period after completion of treatment, and another five, two and three occurred 6,12 and 18 months after surveillance. Old skin lesions became clinically active in five and increased in size in three, new skin patches appeared in two and recurrence of foot drop in three was noted at RFC or during surveillance. A further 6 months of PBR-MDT (paucibacillary regimen) was given to seven children. Treatment with MBR/MDT was started in the other six children. In three, foot drop had recurred; one of them relapsed with a positive repeat skin smear. Multiple new patches had appeared in one child and clinical assessment and skin biopsy confirmed the presence of active disease in another. One child, a girl, who had 11 patches and negative skin smears when first detected, left the area after receiving 16 pulses of MBR-MDT. She returned to the study area 3 years later with positive skin smears. She was restarted on MBR-MDT.

\section{REACTIONS}

Among MB patients one child had six to seven episodes of erythema nodosum leprosum (ENL) reaction apart from one episode of reversal reaction. Two children had two episodes of reversal reaction each and one child had one episode of reversal reaction. All responded well to steroids. Twenty-nine children with paucibacillary disease had reversal reactions or/and neuritis. An episode of reversal reaction in skin was noted in 14 children at detection, in eight during MDT, in another eight during surveillance and in nine after releasing from control. Only five of these patients had reversal reaction in skin alone. Neuritis was observed in 13 children at detection, in seven during surveillance and in eight after release from control. Nerve abscess occurred in three cases during treatment, and in four during surveillance; all of them received a WHO recommended course of steroids. Clawing was observed in four cases, 
which included two children with purely neuritic leprosy (PNL) and two children with borderline tuberculoid who had severe motor weakness with repeated neuritis. This did not improve with steroids and $\mathrm{PB}$ regimen and hence required surgery.

SELF HEALING

Seven cases were assumed to have self healed, as they were inactive at the time of detection till the end of 1996.

\section{Discussion}

Comparison of current data with that of surveys done earlier in the same geographic area reveals that while the incidence of leprosy in children has remained static, the proportion of multibacillary cases has declined significantly. ${ }^{10,13}$ The lepromatous index (LI) declined from 3.7 in 1966 to $0 \cdot 13$. Whether this is due to observer variations, effect of MDT or other operational factors or changing epidemiology of the disease needs further investigation.

Incidence rates among members of leprosy affected families living under the same roof have been shown to be higher than those in the general population; ${ }^{14,15}$ such rates have increased further with multiple cases in the family. While this is reflected in the present study, it is a matter of concern that more than $50 \%$ of young children have reported no household contact. This requires a wider definition of household contacts to include neighbourhood contacts as well as more detailed questioning on possible source of infection. Such cases have a challenging role for intensive epidemiological investigations using modern laboratory technology, on possible environmental and nutritional factors that are likely to compromise the immunity of the children.

The study revealed maximum incidence rates among children aged 10-14 years. Given a long incubation period, it can be inferred that younger children are indeed at the greatest risk. Often such children showing any typical sign are ignored as if they cannot harbour the bacteria. ${ }^{16}$ The more recent evidence that indeterminate leprosy is a precursor of lepromatous leprosy ${ }^{17}$ does indeed emphasize the need for greater caution in ruling out leprosy among young children, and strengthens the need for less invasive diagnostic tests.

The study confirms that most children have only a single lesion, and reveals the difficulties in classifying children with a single large patch over the wrist or forearm. A few of these children have had repeated reversal reactions and deformities as a consequence. Could they have done better on an MB regimen and the early use of steroids? Children with multibacillary disease are also at higher risk for reversal reactions. They require regular follow-up and prompt use of steroids for the prevention of deformity. At the present time, there is no system for the follow-up of children with multibacillary disease who migrate out of the area. This leaves the possibility of their transmitting the disease to others.

More efficient surveys in detecting cases of leprosy as early as possible among both younger and older children are urgently needed. ${ }^{18}$ The present methods are not only inefficient but inadequate. Girls usually drop out of school earlier than boys and are missed during routine school surveys. Intensive sample surveys using modern laboratory techniques would be valuable in studies of childhood leprosy to unravel some of the mysteries in transmission of the disease. ${ }^{19}$ Follow-up strategies for early detection of neuritis are also imperative to prevent nerve damage at such an early age. 
Adequate leprosy control requires not just availability of MDT, but other essential arrangements for early case finding, diagnosis of relapse, detection of reactional states, etc. Much credit has been given to MDT for the dramatic reduction in prevalence of leprosy worldwide, ${ }^{20}$ but this is mainly due to shortening of the duration of treatment and the registerclearing that has accompanied its introduction. It is changes in incidence rather than prevalence that provide evidence that the transmission of disease is being interrupted. ${ }^{21,22}$ The present study does not support the conclusion that leprosy is fading out and emphasizes the need to monitor the magnitude and profile of childhood leprosy in order to understand better its epidemiology and control.

\section{Acknowledgment}

The authors are grateful to all the staff of the Institution who have helped in data collection, compilation and analysis.

\section{References}

${ }^{1}$ Rao PSS, Karat ABA, Kaliaperumal VG, Karat S. Transmission of leprosy within households. Int J Lepr, 1975; 43: 45-54.

2 Kirchheimer WF. Animal models for research in leprosy. Lepr Ind, 1973; 45: 6-11.

${ }^{3}$ Rees RJW, McDougall AC. Airborne infection with Mycobacterium leprae in mice. J Med Micro, $1977 ; 10$ : 63-68.

4 Ridley JC. The presence of M. leprae in human milk. Lepr Rev, 1967; 38: 239-242.

5 Porritt RJ, Olsen RS. Two simultaneous cases of leprosy developing in tattoos. Am J Pathol, 1947; 23: 805-817.

${ }^{6}$ Narayanan E, Manja KS, Bedi BMS, Kirchheimer WF, Balasubrahmanyan M. Arthropod feeding experiments in lepromatous leprosy. Lepr Rev, 1972; 43: 188-193.

7 Nadkarni NJ, Grugni A, Kini MS, Balakrishnan M. Childhood leprosy in Bombay: a clinico-epidemiological study. Ind J Lepr, 1988; 60: 173-188.

${ }^{8}$ Ganapati R, Naik SS, Acharekar MY, Pade SS. Leprosy endemicity in Bombay: an assessment through surveys of municipal schools. Lepr Rev, 1976; 47: 127-131.

9 Dave DS, Agarwal SK. Prevalence of leprosy in children of leprosy parents. Ind J Lepr, 1984; 56: 615-621.

10 Karat ABA, Sadananda G Rao, Karat S, Job CK. Epidemiological studies in leprosy in Gudiyatham Taluk. Part 1. Lepr Rev, 1967; 38: 77-82.

11 Ridley DS, Jopling WH. Classification of biopsy according to immunity. A five group system. Int J Lepr, 1966; 34: 255-273.

12 World Health Organization. Report of a study group chemotherapy of leprosy for control programmes. WHO Tech Rep Series, 1982; 675: 21-26.

${ }^{13}$ Rao PSS, Karat ABA, Kaliaperumal VG, Karat S. Prevalence of leprosy in Gudiyatham Taluk, South India - Part 1. Specific rates with reference to age, sex and type. Int J Lepr, 1972; 40: 157-163.

14 Jesudasan K, Bradley D, Smith PB, Christian M. Incidence rates of leprosy among household contacts of primary cases. Lepr Ind, 1984; 56: 600-614.

15 Rao PSS, Jesudasan K, Mani K, Christian M. Impact of MDT on incidence rates of leprosy among household contacts. Part 1. Baseline data. Int J Lepr, 1989; 57: 647-651.

16 Brubaker ML, Meyers WM, Bourland J. Leprosy in children one year of age and under. Int J Lepr, 1985; 53: 517-523.

17 JobCK, Baskaran B, Joseph J, Aschhoff M. Histopathologic evidence to show that indeterminate leprosy may be a primary lesion of the disease. Int J Lep, 1997; 65: 443-449.

18 Fine PEM. Leprosy: the epidemiology of a slow bacterium. Epidemiol Rev, 1982; 4: 161-170.

19 Dayal R, Bharadwaj VP. Prevention and early detection of leprosy in children. J Trop Paed, 1995; 41: $132-138$.

${ }^{20}$ Noordeen SK. Elimination of leprosy as a public health problem. Lepr Rev, 1992; 63: 1-4.

${ }^{21}$ WHO study group. Epidemiology of leprosy in relation to control TRS 716. WHO, Geneva, 1985.

22 Jakeman P, Smith WCS. Evaluation of multidrug therapy programme of leprosy control. Lepr Rev, 1994; 65: 289-296. 